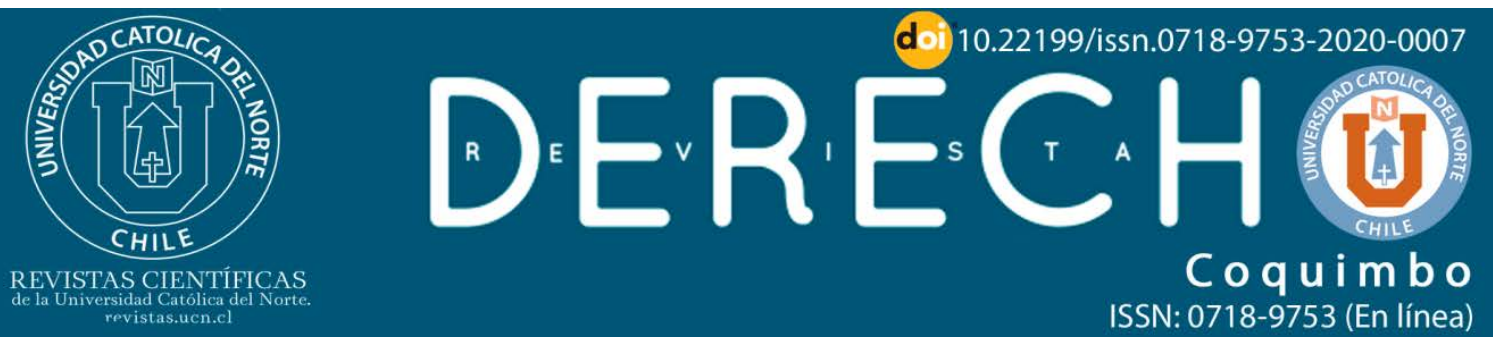

\title{
La postura unánime del Tribunal Constitucional Español (Sentencia Rol 259/2015, de 2 de diciembre)
}

\section{The unanimous approach of the Spanish constitutional court (Ruling No. 259/2015, December 2)}
Alejandro Villanueva Turnes ${ }^{1}$ Dhttps://orcid.org/0000-0002-8044-6189
${ }^{1}$ Universidad de Santiago de Compostela, Galicia, España. Departamento de Derecho Público y Teoría del Estado.
@alejandro.villanueva@usc.es
(cc) BY

\section{Resumen:}

España, que es denominada Estado de las Autonomías, es uno de los países más descentralizados que existen en la actualidad. Este modelo establecido se ha visto cuestionado por diferentes sectores en los últimos años. El presente trabajo supone la exposición de un comentario a una Sentencia del Tribunal Constitucional Español que data del año 2015. La misma no es otra cosa que el resultado de una impugnación contra la Resolución 1/XI, de 9 de noviembre, del Parlamento de la Comunidad Autónoma de Cataluña. De esta manera se podrá ver la posición de las partes y la postura que finalmente adopta el Tribunal.

Palabras Clave: Jurisprudencia constitucional; Estado autonómico; Principio de unidad.

\begin{abstract}
:
Spain, also known as State of Autonomies, is one of the most decentraliced countries, and some people have been questioning this model in the last years. This work is a comment of a sentence of the Constitutional Court from 2015. This sentence arises from a contestation against the Resolution 1/XI, of November 9th, of the Regional Parliament of Catalonia. This work details the positions of both sides and the final ruling of the Constitutional Court.

Keywords: Constitutional jurisprudence; Autonomic State; Principle of unity.
\end{abstract}




\section{Introducción}

Dentro del ordenamiento jurídico español, la Constitución de 1978 establece que:

El Gobierno podrá impugnar ante el Tribunal Constitucional las disposiciones y resoluciones adoptadas por los órganos de las Comunidades Autónomas. La impugnación producirá la suspensión de la disposición o resolución recurrida, pero el Tribunal, en su caso, deberá ratificarla o levantarla en un plazo no superior a cinco meses. (art. 161, inc. 2)

Por su parte, la Ley Orgánica del Tribunal Constitucional señala que: "Dentro de los dos meses siguientes a la fecha de su publicación o, en defecto de la misma, desde que llegare a su conocimiento, el Gobierno podrá impugnar ante el Tribunal Constitucional las disposiciones normativas sin fuerza de Ley y resoluciones emanadas de cualquier órgano de las Comunidades Autónomas" (Ley Orgánica 2/1979, art. 76). Con esto, puede verse claramente la competencia existente para realizar una impugnación ante el Supremo Intérprete de la Constitución en relación a las Resoluciones autonómicas, cuando se considere que su contenido resulta contradictorio con lo establecido en la Norma Normarum. Estos preceptos, son los que sirven de fundamento para la impugnación que da como resultado la Sentencia que se va a examinar a continuación.

Concretamente, nos encontramos con la Resolución 1/XI, de 9 de noviembre de 2015, sobre el inicio del proceso político en Cataluña como consecuencia de los resultados electorales del 27 de septiembre de 2015, aprobada por el Parlamento de Cataluña, que pretendía dar pie a la creación de un nuevo Estado en la Comunidad Autónoma, y la cual ha sido objeto de impugnación por parte del Gobierno de la Nación ante el Tribunal Constitucional.

\section{Postura del recurrente}

El Abogado del Estado, en representación del Gobierno de la Nación, expresa que la Resolución que se impugna es un acto definitivo y que no es simplemente una declaración política, sino que tiene también efectos jurídicos, estableciendo al Parlamento de Cataluña como un poder constituyente. A su vez, considera que la Resolución del Parlamento catalán, que debe ser interpretada en su conjunto como un todo, atenta contra los principios constitucionales y contra el propio Estado de Derecho, poniendo de manifiesto que se trata de la continuación de una serie de decisiones que se han ido adoptando paulatinamente, en relación con el intento de romper con el resto del Estado.

La impugnación se centra en las siguientes vulneraciones: 
El inicio de un nuevo proceso constituyente, tal y como se plantea en la Resolución, rompe con los principios del Estado de Derecho, Estado que se proclama en el artículo 1.1 de la Constitución, vulnerando este precepto y la manifestación clara del mismo proclamada en el artículo 9.1 de la misma norma, que es la sujeción de ciudadanos y poderes a la Constitución y ordenamiento jurídico.

Se recalca la soberanía del pueblo español proclamado en el artículo 1.2 del Texto Constitucional, artículo que se vería vulnerado al considerarse al Parlamento de Cataluña como un depositario de la soberanía y considerarlo como una expresión del poder constituyente, encontrando esto una fundamentación derivada de las elecciones que han tenido lugar en la Comunidad Autónoma de Cataluña.

Otra vulneración, se encuentra en que la Resolución hace mención a la creación de un Estado independiente que se califica de República, cosa que contradice el apartado tercero del artículo 1 de la Constitución.

La Resolución, es considerada contraria de forma inevitable con el artículo 2 de la Norma Superior del ordenamiento jurídico, ya que al otorgar el carácter constituyente al Parlamento Catalán, se le otorga una capacidad para tomar decisiones que pueden provocar la ruptura con la patria común e indivisible proclamada en el precepto constitucional, lo cual es el propio fundamento de la Carta Magna.

La Resolución también manifiesta una clara intención de no someterse a las decisiones del Alto Tribunal, vulnerando por un lado el artículo 164 de la Constitución, y por otro el artículo 87 de la Ley Orgánica de dicho órgano.

También se expone una vulneración del artículo 168 de la Norma Constitucional, puesto que, según el recurrente, lo que debería hacerse para que el ente autonómico pueda constituirse por sí mismo en un Estado, sería realizar de forma previa una reforma de la Constitución mediante el procedimiento agravado y, una vez realizada la mencionada reforma constitucional siguiendo el procedimiento destinado a tal efecto, se podría proceder de forma correcta.

Unido a esto, también se establece una infracción del derecho fundamental reconocido en el artículo 23 de la Constitución, no permitiendo a los ciudadanos participar en procedimientos de Reforma y participación en asuntos públicos, provocando una modificación de los principios y procedimientos característicos de una democracia representativa.

El Abogado del Estado, también considera que se vulnera un principio y un deber importantes en el ámbito jurídico, siendo estos el principio de lealtad constitucional y el deber de fidelidad hacia la Constitución.

Fuera de la Norma Superior del Ordenamiento, también se señala una serie de vulneraciones respecto del Estatuto de Autonomía de Cataluña. Así, se considera que 
se están vulnerado los artículos 1, 2.4 y 4.1, que fueron interpretados por la Sentencia del Tribunal Constitucional 31/2010, dictada para dar respuesta al recurso de inconstitucionalidad presentado contra el Estatuto de Autonomía.

La última vulneración recalcada por el Abogado del Estado, se refiere al sistema de competencias constitucionalmente establecido, refiriéndose a las materias de Hacienda Pública y Seguridad Social, y acaba señalando al mismo tiempo que en la Resolución se plasma la intención de realizar un incumplimiento de la normativa estatal.

Como peticiones, el Abogado del Estado solicita la admisión a trámite, la declaración de inconstitucionalidad de la Resolución impugnada. Añadiendo dos peticiones más, una relativa a la suspensión de la Resolución y otra a la realización de una notificación personal de la suspensión.

El Tribunal Constitucional decide admitir a trámite la impugnación, suspender la Resolución y proceder a la notificación solicitada.

\section{Pronunciamiento del Tribunal y justificación}

Como punto de partida, es necesario destacar que el Tribunal Constitucional va a estimar la impugnación y declarar la inconstitucionalidad de la Resolución y su nulidad.

El Alto Tribunal, ha recordado que para la impugnación de este tipo de Resoluciones en las que hay un marcado carácter político, se requiere una naturaleza jurídica, proviniendo de un órgano legitimado para expresar la voluntad de la Comunidad Autónoma, que pueda producir efectos jurídicos y que no sea un acto de trámite. Todo ello se cumple en relación con la Resolución impugnada. Además, se considera que la Resolución es un todo y la enjuicia como tal.

El Tribunal Constitucional determina que, con la Resolución impugnada en la mano, se puede apreciar que se han excluido aquellos procedimientos constitucionalmente establecidos para llevar a cabo las aspiraciones que se puedan tener, manifestado de forma clara que "recae sobre los titulares de cargos públicos un cualificado deber de acatamiento a dicha norma fundamental, que no se cifra en una necesaria adhesión ideológica a su total contenido, pero sí en el compromiso de realizar sus funciones de acuerdo con ella y en el respeto al resto del ordenamiento jurídico" (Sentencia 259/2015, FJ 4, b).

A su vez, recalca el Tribunal la necesidad de que el principio democrático conviva con la primacía de la Constitución en todo Estado Constitucional. 
En los Fundamentos, se hace referencia a la contradicción existente entre la Constitución Española y el propio Estatuto de Autonomía de Cataluña, respecto de la formulación del principio de legitimidad democrática que hace el Parlamento de Cataluña en su Resolución junto con las consecuencias que tiene. Concretamente se dice:

En el Estado social y democrático de Derecho configurado por la Constitución de 1978 no cabe contraponer legitimidad democrática y legalidad constitucional en detrimento de la segunda: la legitimidad de una actuación o política del poder público consiste básicamente en su conformidad a la Constitución y al ordenamiento jurídico. Sin conformidad con la Constitución no puede predicarse legitimidad alguna. En una concepción democrática del poder no hay más legitimidad que la fundada en la Constitución. (Sentencia 259/2015, FJ 5)

En este punto, incide el Constitucional en que la Constitución es sin lugar a dudas una garantía de la democracia, y es que por la forma de creación y aprobación así lo es, y además no se trata de una norma inalterable sino que presenta mecanismos de reforma, de tal manera que "... el ordenamiento jurídico, con la Constitución en su cúspide, en ningún caso puede ser considerado como límite de la democracia, sino como su garantía misma" (Sentencia 259/2015, FJ 5).

A lo largo de la Sentencia se hace referencia, como no podía ser de otro modo, a la soberanía nacional que tiene el pueblo español, y se dice que:

...se trata de un Estado también único o común para todos y en todo el territorio, sin perjuicio de su articulación compuesta o compleja por obra del reconocimiento constitucional de autonomías territoriales [...] a las distintas nacionalidades y regiones que, constituidas en Comunidades Autónomas en virtud de sus respectivos Estatutos, integran España... (Sentencia 259/2015, FJ 4, a)

El Tribunal Constitucional no llega a analizar todas las impugnaciones que realiza el recurrente, sino que al considerar vulnerados una serie de preceptos (concretamente los artículos 1.1, 1.2, 2, 9.1 y 168 CE, y el artículo 1 y 2.4 EAC), dictamina que no es necesario examinar el resto de los artículos invocados en la impugnación, de tal manera que estos van a ser suficientes para anular la Resolución.

\section{Comentario final}

Dados los acontecimientos que están teniendo lugar en España en relación con la Comunidad Autónoma de Cataluña, la Sentencia del Tribunal Constitucional que acaba de analizarse se vuelve sumamente relevante como complemento al entendimiento de la situación actual. De esta manera, puede apreciarse como el Alto 
Tribunal da continuidad a una serie de pronunciamientos que comenzaron en el año 2013 con la Resolución 5/X del Parlamento, de 15 de enero de 2013, por la que se aprobó la Declaración soberanista y el derecho a decidir del pueblo de Cataluña. Lejos queda la polémica Sentencia 31/2010 que resolvía el recurso de inconstitucionalidad del Estatuto de Autonomía de Cataluña y que abusaba claramente de la técnica de la interpretación conforme. Si bien es cierto que a partir de esta Resolución, que no dejó a nadie indiferente, se ha utilizado, con acierto, la interpretación conforme como sucede en el año 2014 (Sentencia 42/2014), en la Sentencia que se comenta aquí, esta técnica resultaba inaplicable, ya que con la Carta Magna en la mano, la inconstitucionalidad de la Resolución era evidente. El máximo intérprete de la Constitución realiza un análisis con plena lógica jurídica, fundamentando su decisión de forma implacable. Es conveniente aclarar, que el hecho de que el Tribunal no analice todos los preceptos señalados por el recurrente, guarda sentido con el hecho de considerar la Resolución como un todo, coincidiendo con el Tribunal en que los preceptos vulnerados son más que suficientes para la declaración de inconstitucionalidad.

La unanimidad manifestada en la decisión de declarar la inconstitucionalidad de la Resolución, muestra a su vez una clara postura en relación al respeto a la Norma Superior del Ordenamiento Jurídico y por ende al Estado de Derecho (debemos aclarar que, ésta unanimidad, se ha podido observar en otros temas relacionados con la Comunidad Autónoma de Cataluña con posterioridad a la Sentencia que se analiza aquí. De esta manera puede verse como sucede, por ejemplo, en la Sentencia 114/2017, de 17 de octubre, dirigida contra la Ley del Parlamento de Cataluña 19/2017, de 6 de septiembre, denominada "del referéndum de autodeterminación"; o la Sentencia 51/2017, de 10 de mayo, contra determinados preceptos de la Ley del Parlamento de Cataluña 4/2010, de 17 de marzo, de consultas populares por vía de referéndum). Bien es cierto que para que el órgano que ha dictado la Resolución impugnada, esto es, el Parlamento de Cataluña, el Tribunal Constitucional los redirecciona hacia la vía de la reforma constitucional, la cual puede ser propuesta por un organismo autonómico, de tal manera que "Es plena la apertura de la norma fundamental para su revisión formal, que pueden solicitar o proponer, entre otros órganos del Estado, las asambleas de las Comunidades Autónomas..." (Sentencia 259/2015, FJ 7). Esta "sugerencia" por parte del Constitucional es adecuada y racional, ya que con ella no se hace otra cosa que señalar una vía legítima y admisible desde el punto de vista jurídico, para conseguir los objetivos que pueda tener el órgano autonómico siguiendo la legalidad. Esto recuerda la famosa frase que dice que siempre se debe pasar de la Ley a la Ley pasando por la Ley. 


\section{Referencias Bibliográficas}

Constitución Española. Boletín Oficial del Estado, Madrid, España, 29 de diciembre de 1978. Recuperado de https://bit.ly/2xg6S6S

Ley Orgánica 2/1979 del Tribunal Constitucional. Boletín Oficial del Estado, Madrid, España, 3 de octubre de 1979. Recuperado de https://bit.ly/3b2jZ9R

Sentencia 31/2010, Recurso de inconstitucionalidad 8045-2006, ECLI:ES:TC:2010:31 (Tribunal Constitucional de España 28 de junio 2010). Recuperado de https://bit.ly/2L4CvDL

Resolución 1/XI sobre el inicio del proceso político en Cataluña como consecuencia de los resultados electorales del 27 de septiembre de 2015, Parlamento de Cataluña, Barcelona, 9 de noviembre de 2015. Recuperado de https://bit.ly/2zSDzIE

Resolución $5 / X$ por la que se aprueba la Declaración de soberanía y del derecho a decidir del pueblo de Cataluña, Parlamento de Cataluña, Barcelona, 23 de enero de 2013. Recuperado de https://bit.ly/2T55P1n

Sentencia 259/2015, Impugnación de disposiciones autonómicas 6330-2015, ECLI:ES:TC:2015:259 (Tribunal Constitucional de España 2 de diciembre 2015). Recuperado de https://bit.ly/3fj295Q

Sentencia 42/2014, Impugnación de disposiciones autonómicas 1389-2013, ECLI:ES:TC:2014:42 (Tribunal Constitucional de España 25 de marzo 2014). Recuperado de https://bit.ly/3d9PX5o

Sentencia 114/2017, Recurso de inconstitucionalidad 4334-2017, ECLI:ES:TC:2017:114 (Tribunal Constitucional de España 17 de octubre 2017). Recuperado de https://bit.ly/3c7foEO

Sentencia 51/2017, Recurso de inconstitucionalidad 8912-2010, ECLI:ES:TC:2017:51 (Tribunal Constitucional de España 10 de mayo de 2017). Recuperado de https://bit.ly/2KVZ1yK

\section{Para citar este artículo bajo Norma APA 6a ed. \\ Villanueva Turnes, A. (2020). La postura unánime del Tribunal \\ Constitucional Español (Sentencia Rol 259/2015, de 2 de diciembre). Revista de Derecho (Coquimbo. En línea), 27, e4175, https://doi.org/10.22199/issn.0718-9753-2020-0007}

Copyright del artículo: @2020 Alejandro Villanueva.

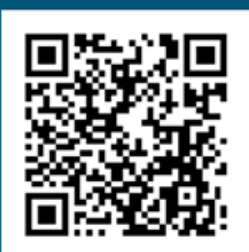

DOI

Este es un artículo de acceso abierto, bajo licencia Creative Commons BY 4.0. 